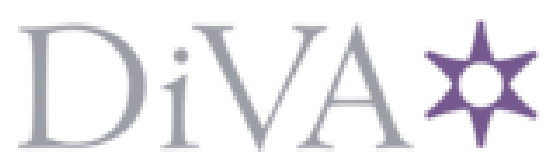

http://www.diva-portal.org

\title{
Postprint
}

This is the accepted version of a paper published in European Journal of Engineering Education. This paper has been peer-reviewed but does not include the final publisher proof-corrections or journal pagination.

Citation for the original published paper (version of record):

Berge, M., Weilenmann, A. (2014)

Learning about friction: group dynamics in engineering students' work with free body diagrams.

European Journal of Engineering Education, 39(6): 601-616

http://dx.doi.org/10.1080/03043797.2014.895708

Access to the published version may require subscription.

N.B. When citing this work, cite the original published paper.

This is an Author's Accepted Manuscript of an article published in European Journal of Engineering Education, 12 Mars 2014. Available online at: http://www.tandfonline.com/doi/ abs/10.1080/03043797.2014.895708

Permanent link to this version:

http://urn.kb.se/resolve?urn=urn:nbn:se:umu:diva-87435 
This article was downloaded by: [Umeå University Library]

On: 01 April 2014, At: 01:22

Publisher: Taylor \& Francis

Informa Ltd Registered in England and Wales Registered Number: 1072954 Registered

office: Mortimer House, 37-41 Mortimer Street, London W1T 3J H, UK

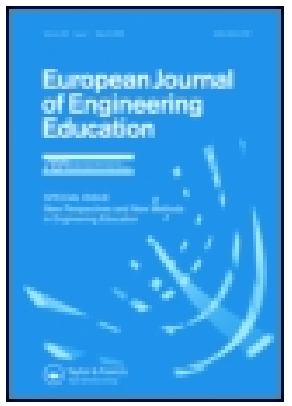

\title{
European J ournal of Engineering Education
}

Publication details, including instructions for authors and subscription information:

http:// www.tandfonline.com/loi/ ceee20

\section{Learning about friction: group dynamics in engineering students' work with free body diagrams}

\author{
Maria Berge ${ }^{a} \&$ Alexandra Weilenmann ${ }^{b}$ \\ a Department of Science and Mathematics Education, Umeå \\ University, Umeå, 901 87, Sweden \\ ${ }^{b}$ Department of Applied IT, University of Gothenburg, Göteborg, \\ Sweden \\ Published online: 12 Mar 2014.
}

To cite this article: Maria Berge \& Alexandra Weilenmann (2014): Learning about friction: group dynamics in engineering students' work with free body diagrams, European J ournal of Engineering Education, DOI: 10.1080/03043797.2014.895708

To link to this article: http:/ / dx. doi.org/ 10.1080/ 03043797.2014.895708

\section{PLEASE SCROLL DOWN FOR ARTICLE}

Taylor \& Francis makes every effort to ensure the accuracy of all the information (the "Content") contained in the publications on our platform. However, Taylor \& Francis, our agents, and our licensors make no representations or warranties whatsoever as to the accuracy, completeness, or suitability for any purpose of the Content. Any opinions and views expressed in this publication are the opinions and views of the authors, and are not the views of or endorsed by Taylor \& Francis. The accuracy of the Content should not be relied upon and should be independently verified with primary sources of information. Taylor and Francis shall not be liable for any losses, actions, claims, proceedings, demands, costs, expenses, damages, and other liabilities whatsoever or howsoever caused arising directly or indirectly in connection with, in relation to or arising out of the use of the Content.

This article may be used for research, teaching, and private study purposes. Any substantial or systematic reproduction, redistribution, reselling, loan, sub-licensing, systematic supply, or distribution in any form to anyone is expressly forbidden. Terms \& 
Conditions of access and use can be found at http://www.tandfonline.com/page/termsand-conditions 


\title{
Learning about friction: group dynamics in engineering students' work with free body diagrams
}

\author{
Maria Berge $^{\mathrm{a} *}$ and Alexandra Weilenmann ${ }^{\mathrm{b}}$ \\ ${ }^{a}$ Department of Science and Mathematics Education, Umeå University, Umeå, 901 87, Sweden; \\ ${ }^{b}$ Department of Applied IT, University of Gothenburg, Göteborg, Sweden
}

(Received 29 October 2013; accepted 6 February 2014)

\begin{abstract}
In educational research, it is well-known that collaborative work on core conceptual issues in physics leads to significant improvements in students' conceptual understanding. In this paper, we explore collaborative learning in action, adding to previous research in engineering education with a specific focus on the students' use of free body diagrams in interaction. By looking at details in interaction among a group of three engineering students, we illustrate how they collectively construct a free body diagram together when learning introductory mechanics. In doing so, we have focused on both learning possibilities and the dynamic processes that take place in the learning activity. These findings have a number of implications for educational practice.
\end{abstract}

Keywords: free body diagram; collaborative learning; problem solving; mechanics; conversation analysis

\section{Introduction}

Engineering students are expected to learn how to work in teams and have interpersonal, creative and critical thinking skills, problem-solving abilities, logical and analytical decision-making skills because it is 'needed to work in today's workplace' (Sahin 2010, 519). Sahin writes further that engineering students are also expected to have a good conceptual understanding of basic sciences, including physics. It is well documented that collaborative work around core conceptual issues in physics lead to significant improvement in students' conceptual understanding (Heller and Hollabaugh 1992a; Redish 2003). It is, therefore, not surprising that different forms of active learning such as problem-based learning (PBL) and collaborative learning have been implemented in engineering education as a radical change from traditional instruction (Prince 2004): there is broad (but uneven) support for these teaching forms in engineering education research. However, as pointed out by Scherr and Hammer (2009), there has been little direct attention to what 'actually happens' on a micro-level during these instructional activities around physics concepts. Likewise, there has been a call for better understanding for what happens in engineering education 'in more depth' (Case and Light 2011; Johri and Olds 2011). The objective of this paper is, therefore, to further contribute to our understanding of collaborative learning in engineering education by looking at details when students solve physics problems together, thus, to contribute to the field of engineering education research. In this paper, we aim to shed light on how engineering students

*Corresponding author. Email: maria.berge@umu.se 
produce a free body diagram together, and we use an analytical tool that is not traditionally used in this field of research: conversation analysis (CA). This approach allows us to investigate the group work in its unfolding details, focusing on how questions are solved in interaction between the group members and with the resources available.

\subsection{Learning together}

Collaborative learning can refer to an instructional method in which students work together in small groups towards a common goal and PBL is an instructional method where problems are introduced at the beginning of the instruction cycle. PBL is usually collaborative and PBL is regarded and implemented as a successful and innovative method for engineering education (De Graaff and Kolmos 2003; Prince 2004). Both PBL and collaborative learning are well-discussed issues in engineering education research. For example, Sahin (2010) has illustrated how engineering students gained conceptual learning gains with PBL and Macho-Stadler and Jesús Elejalde-García (2013) have shown that the attitude of engineering students was improved and the class attendance level increased when PBL-based education was implemented. These results are based on quantitative research in the form of pre- and post- tests or questionnaires, in line with the tradition of focusing on student knowledge construction in science education research. There is also a big field of engineering education research that describes implementation of active learning. For example, Oliveira and Oliveira (2013) have illustrated how introduction of conceptual questions in engineering education can promote active learning and thereby result in higher motivation among students. Similarly, Waller and Kaye (2012) have explained how an engineering course was developed with a collaborative teaching approach which had an impact on students learning. Kolmos et al. (2013) described how PBL creates a learning environment that students 'appreciate as an important facilitator in their learning process' (343).

However, there is a strand of video research that illustrate how groups of students are not 'productive' in every moment when they solve physics problems together: the students may talk off topic (Scherr and Hammer 2009) or the students might get stuck in the problem-solving process (Benckert and Pettersson 2008; Ingerman, Berge, and Booth 2009). The students' (sometimes collective) approaches to the task when solving physics problems influenced the learning possibilities when learning together (Berge and Danielsson 2013; Berge, Danielsson, and Ingerman 2012). Two described approaches among engineering students were 'Deal with the physics problems in terms of reaching a solution' and 'Deal with the physics problems in terms of understanding the physics'. There were benefits and drawbacks with both these approaches. A strong focus on solving the task made it more probable that the group would work more quickly and thereby cover more physics content. When the group had a strong focus on understanding the problems, the learning space opened up, with the benefit of more learning possibilities. Previous research affords recommendations for how collaborative work around physics concepts should be conducted: three- and four-member groups generate the best solutions (Benckert and Pettersson 2008; Heller and Hollabaugh 1992b). Heller and Hollabaugh (1992b) also recommend that the students discuss what they could do the next time to improve their 'group functioning' and to define and assign students-specific roles, such as the 'manager' the 'sceptic' and the 'recorder'.

\subsection{Free body diagrams}

The concept of free body diagrams is taught in introductory mechanics courses in lectures, tutorials and books. Despite this, students have significant problems with understanding the function of vectors in a free body diagram (Flores, Kanim, and Kautz 2004). Free body diagrams are used by physicists and engineers as external representations to analyse forces. Being able to use a free 
body diagram is a fundamental part of learning physics in higher education (Airey 2009). Since an understanding of forces is a representational issue, the students' individual sense-making of forces cannot only be based on what is said, but should also be based on what the students do (Hubber, Tytler, and Haslam 2010). Thus, free body diagrams are of highest interest when studying what students do together when learning mechanics.

\subsection{Research questions}

Cooperative learning and PBL are popular instructional activities, often described in engineering education research. However, previous research in engineering education has mainly been quantitative and the results have often been in forms of suggestions on how to achieve better learning outcomes and descriptions of improvements of specific educational programmes. Little attention has been paid to the interactional patterns among the students within these processes. In this paper, we want to address this gap in engineering education research, by exploring collaborative learning in action using qualitative data in the form of video recordings of group work. Also, we want to discern how a free body diagram is used in interaction when solving physics problems together with a focus on the interactional accomplishments, using CA. In other words, this study, rather than focusing on what the students learn, will investigate how the free body diagram is used in a learning context. More specifically, we are interested in: What are the interactional patterns when engineering students work with core conceptual issues in physics? Which role does a free body diagram play in the interaction?

\section{Methods}

Empirical data were collected as a part of a bigger project in which engineering students from a Swedish university solved two physics problems in constellations of three to four students. The students observed in this study came from the Engineering Physics programme, in the middle of their first year and their first course in mechanics that aims to lay an important foundation for the following physics courses. The groups were video-recorded and interviewed afterwards. Video recording has several advantages: it enables researchers to capture detailed versions of action, activity and interaction that are largely unavailable to an observer (Hindmarsh and Heath 2007). In total seven hour-long group sessions were recorded for further details about data collection, see Berge (2011). The project had an openness in its research design in terms of the pedagogical setup - only the sheet of instruction, the group setting and the time limit one hour were given, while the ways the students organised their work, including the extent to which course literature was used, etc., were left open. The sheet of instructions containing physics questions concerning force and friction. The first part that is relevant for this paper is shown in Figure 1.

The physics questions originate from previous research on students' conceptual knowledge (see, for example, the study by Hestenes, Wells, and Swackhamer 1992) and are relevant to students in engineering education. The questions in the first part may seem trivial at first though they are not; there is a hidden complexity that does not meet the eye. The key difficulty is to grasp the counter intuitive fact that the friction force on the ox's hooves is directed forward. Since the ox is moving with a constant velocity, the sum of all horizontal forces should be equal to zero, which in this case breaks down to that the forces can be paired as equal in magnitude and opposite in direction in a correct free body diagram; All groups solved these questions by producing free body diagrams.

As mentioned, all students constructed free body diagrams and they did so in the beginning of the group sessions. However, different groups organised their work differently; some groups chose a shared response sheet, while others chose to work on individual shared response sheets. For this 


\section{Problems for group session in Introductory Mechanics}

NB! When you solve the problems, try to finish your discussions before you start any calculations.

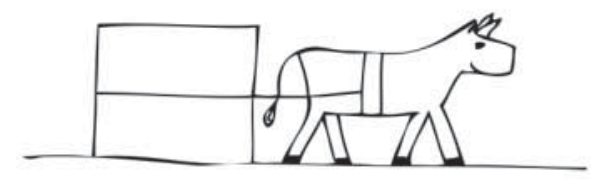

An ox is pulling a box with constant velocity.

* Which forces are acting on the ox and the box and how are they related to one another?

${ }^{\star}$ Which of these forces affect the movement of the ox and the box?

* Think about how the ox's and the box's mass matter. What happens if: the ox doubles its mass?

the box doubles its mass?

${ }^{\star}$ What do the equations of motion look like?

* How is it possible for the ox to move forward?

Figure 1. The sheet of instructions (first part) used in the group sessions described in this paper.

paper, data from one group session was selected that produced one free body diagram collectively in order to solve the physics problems. The group consisted of three physics engineering students, here called Olle, Pia and Rut, see Figure 2. They all knew each other from before and were used to solve physics problems as a group from earlier university courses. In front of them on the table, they all had a sheet of instructions and a pile of blank sheets of paper was placed in the middle of them. The group was video-recorded by means of a video camera that was carefully positioned in the corner of the room in order to pick up body language between the participants and to distinguish how and when the students answered on their response sheet afterwards. An observer (the first author) was present during the recordings. All three students agreed when they were specifically asked for permission to publish pictures of their faces together with related transcripts of their dialogue. The instruction sheet and the conversation were originally in Swedish, but have been translated by the authors.

\subsection{Conversation analysis}

The analytical starting point in this paper is to explicate interactional patterns in the process of constructing a free body diagram as part of a learning activity, and therefore CA was used to approach the empirical material. In the discipline of CA, the emphasis is on renderings of naturally occurring interactional activities in detailed transcripts, rather than on coded or counted representations. This study is in line with the stream of educational research that uses CA to describe and exemplify details in a learning practice in order to better understand it, in this case how three engineering students produce a free body diagram together. CA has been used to explore a range of different practices such as professional mathematical practice (Greiffenhagen 2008), professional astronomy (Koschmann and Zemel 2009) and work-meetings (Mondada 2007), but so far never to explore engineering education. However, a relevant example of the use of CA 


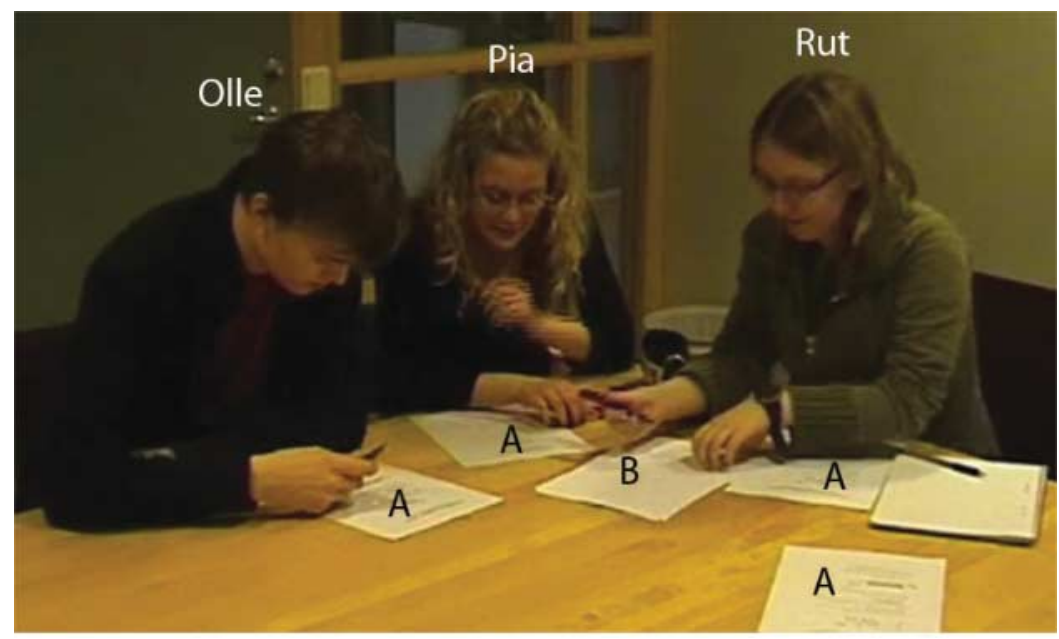

Figure 2. The three students from the left: Olle, Pia and Rut. In front of them are the sheets of instructions (A), and in front of Rut there is a pile of blank sheets of papers (B).

in higher education is Lindwall and Lymer's study (2008) of labs in a specific physics course. In this study, they examined students' interaction when producing and interpreting graphs. They illustrated how the students struggled and the students' difficulties to grasp and to formulate what they did not understand to their instructor. This is the main benefit with CA; it brings attention to the process rather than the outcome.

The first analytical (and crucial) step in the present study was to choose what video data to analyse in depth. In the tradition of CA, the focus is generally on short sequences because of the focus on details. The group session with Olle, Pia and Rut was chosen because this group worked well and the atmosphere was friendly, and it represented the whole data set well. Within this group session a small sequence, which only spans about two minutes was chosen. This particular sequence is from the beginning of the group session, and is chosen because it shows the multiplicity of ways in which free body diagram played a part in the problem-solving process. It is typical in the tradition of CA that talk is seen as 'an emergent collectively organized event' (Have 2007, 9), although the analytic purpose is not to explain why people act like they do but to scrutinise how they do it. Here, CA is used to bring light on the details in what the three students do when they construct a free body diagram, step by step, and how they used the free body diagram (in progress) in their response sheet as a resource (c.f. Goodwin 2000) when they speak with each other.

The second analytical step was to start off with the students' representation of a free body diagram, then tracing backwards in the video data searching for consequences and constraints of the learning situation. Detailed transcripts were made, first in Swedish and then translated into English. The transcripts are made in the tradition of CA and might for someone unfamiliar with the system seem difficult to read, but capture essential details of conversational and embodied interaction such as points at which the turns-at-talk overlap, silence, and so on (cf. Appendix). Following Goodwin's characterisation of CA, we did not only include oral conversation in the empirical base for analysis, but also the students' bodily conduct and how the students made use of artefacts, since all this information is important when communicating in an educational setting. Therefore, the transcripts were attached with figures of reconstructions, made by the first author, of the free body diagram as it looked like in the process to give the reader an idea on how the free body diagram was built up. The third analytical step was to put these interactional patterns into the context of learning physics and engineering education. 


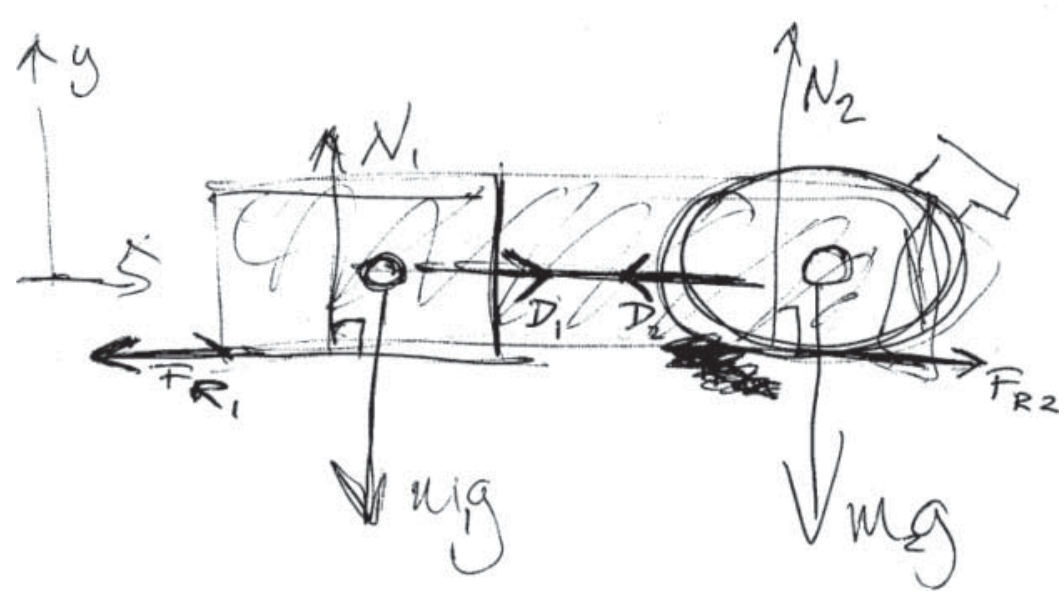

Figure 3. The final free body diagram as produced by the students.

\section{Results}

A free body diagram consists primarily of a sketch of the body in question and arrows representing the forces applied to it, and should include only as much detail as necessary (e.g. internal forces are omitted). The forces are represented by arrows labelled with appropriate names that show the direction of the various forces. In this paper, the students' 'final free body diagram' has all these described features, see Figure 3. Their free body diagram has gravitational forces, $\mathrm{m}_{1} \mathrm{~g}$ on the box and $\mathrm{m}_{2} \mathrm{~g}$ on the ox, and normal forces that 'neutralise' the gravitational forces, the arrows $\mathrm{N}_{1}$ and $\mathrm{N}_{2}$ upwards. The final free body diagram has also a friction force $\mathrm{F}_{R 1}$ backwards on the box and a friction force $\mathrm{F}_{R 2}$ forward on the ox, and two arrows on the rope showing forces from the ox on the box $\mathrm{D}_{1}$ (forward) and from the box on the ox $\mathrm{D}_{2}$ (backward).

In the following sections, six excerpts with transcripts and attached figures together illustrate different facets of the practice of producing this free body diagram together.

\subsection{Establishing the response sheet as collective}

The group session started with a two minute silence, all three students read the task on their three individual instruction sheets. Pia and Rut seemed to finish their reading before Olle, since Pia and Rut both moved impatiently and looked at each other when Olle on the other hand looked down at his instruction sheet and seemed to read for a longer time. When Olle finally looked up, and thereby indicated that he had finished reading, Pia broke the silence:

In this excerpt Pia asked 'what do we say about the first one then?' (line 109) and simultaneously Rut grabbed a blank piece of paper and started drawing an ox and a box, which is a beginning of the free body diagram. Olle and Pia, on the other hand, still looked down on their instruction sheets (see Figure 4). Here Rut took a cooperative stance through language: 'we can just draw here right' (110) but also in her way of organising her body in relation to the response sheet (visible for all). Rut thereby established a public, shared focus of visual and cognitive attention (Goodwin 2007) to the response sheet; at this point, the response sheet became collective instead of individual. Rut addressed the free body diagram as something you 'just draw' (110), and this was said more like a statement than a question, indicating she has done this many times before. However, she continued with 'I guess' which signalled uncertainty and opened up for possible 
101. $\mathrm{P}$ are you: ready?

102. ((Pia looks at Rut, Olle looks down on the sheet of instructions))

103. (1.3)

104. $\mathrm{R}$ each [and] every time

105. 0 [yes]

106. $\mathrm{P} \mathrm{mm}$

107. 0 I am ready

108. (2.5)

109. P what do we say about the first one then? ((Rut grabs piece of paper and starts drawing, see a))

110. $\mathrm{R}$ we can just draw here right

111. (1.3)

112. R I guess

((Rut continues drawing, Olle and Pia watch))

Figure 4. Excerpt 1.

rejections and other comments from Olle or Pia, that never came. Already here, when Rut grabbed a blank piece of paper, Rut acquired a position in their collective interaction that differed from Olle's and Pia's positions. At this point, Rut became the one who expressed her thoughts and views not only through talk but through writing and drawing.

\subsection{Providing an embedded history}

The free body diagram became the first element on their collective response sheet. Rut drew an ox and a box, and then she continued to draw a normal force (see Figure 5(a)).

In the beginning of the second excerpt, Rut made online commentaries (Heritage and Stivers 1999) on what she was doing (201-207). This had two effects: she positioned herself as certain of what she was doing, and she also opened up for comments and opinions. However, this excerpt

201. $\mathrm{R} \mathrm{mm} \mathrm{(0.7)} \mathrm{and} \mathrm{then} \mathrm{there} \mathrm{is} \mathrm{a} \mathrm{(0.5)}$ normal force

202. (3.8)

203. $\mathrm{R}$ and also a

204. (1.5)

205. R gravitational force ((seea))

206. (1.5)

207. $\mathrm{R}>$ should perhaps draw that one on it $\$$ too $\$<(0.6)>$ I usually think like one system so< ( $($ Rut rearranges the force diagram into one box, one system, see b))

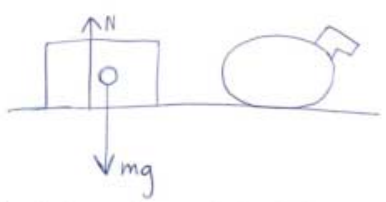

(a) Pia draws the gravitational force 'mg' on the box

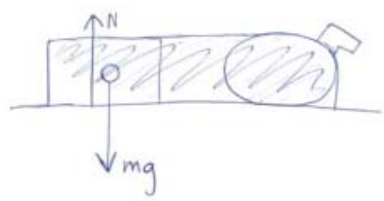

(b) The box and the ox, as 'one system'

Figure 5. Excerpt 2. 
illustrates how Rut communicated much physics through drawing on the response sheet. For example, the picture she made first (see Figure 5(a)) represented two bodies in a free body diagram in this context, which means that she has divided the ox and the box into two systems. It is worth pointing out that Rut also has simplified the ox and box compared to the picture in the sheet of instructions (Figure 1) in the sense that she made the ox without legs, without any comments on it; this information is only in the free body diagram. Likewise, Rut gave the normal force and the gravitational force on the box names in the response sheet, ' $N$ ' and ' $m g$ ', respectively, without any further comments. The free body diagram communicated details about Rut's (and since Olle and Pia did not object, in some sense also the group's) view of normal force and gravitational force. The free body diagram described how these forces are directed, where they started and how big they were compared to each other. In other words, the free body diagram contained important details, and became in some sense more explicit than what the students expressed through language only. In this way, the free body diagram was a publicly visible component of the 'on-going practices' (Goodwin 2000) that was used to build a collective action.

In the end of the excerpt, Rut started to change the free body diagram into one box (see Figure 5(b)), but the idea of 'two systems' was still visible. This shows how the collective response sheet is a dynamic product, with an embedded history of the group's work.

\subsection{Orienting to the instructions}

After Rut changed the free body diagram into one box (see Figure 5(b)), Olle intervened and argued for having two systems instead on one in the free body diagram.

When Olle intervened and argued for two systems, he did so by pointing, (Figure 6(a)). Olle thereby made a gesture that was organised with reference to a specific embodied configuration (Goodwin 2000), which is his sheet of instruction, more specifically the picture of the ox and the box on the top of the sheet. Rut answered him with an agreement (302), but then Rut said that one system is the best way (303), and continued her drawing of only one box, as though she did not hear what Olle said. Pia reacted on this contradiction that indicated a missing understanding and she initiated a repair sequence (Schegloff 1992): she gazed at Olle and then she asked with a 'fast voice' what Olle said before (305). Pia oriented herself to Olle's argument, by pointing at Olle's sheet of instruction (Figure 6(b)), which reinforced her verbal statement. Olle then argued again for two systems: 'well one should check the forces in between too' by pointing at the picture first and then he pointed specifically at the first question in his sheet of instructions (306). Here both Pia and Olle used Olle's sheet of instruction as an artefact to communicate what they mean. Pia continued her repair work and gave Olle a question, a rephrased repetition of what already had been said (308). This question that was directed towards Olle and Olle's answer 'yes' (309) together delivered a message to Rut that this free body diagram, unlike her drawing, should be divided into two systems. Rut changed the free body diagram into two systems again, but the idea of only one system is still visible in Figure 6(c) (see also Figure 3, the final free body diagram).

In this excerpt, the sheet of instruction became a mutual resource when discussing the making of the free body diagram, since both Olle and Pia evoked and reinforced their arguments by pointing at the instruction sheet (Goodwin 2007). When Olle argued for a free body diagram with two systems he referred to the first question (by pointing) on the instruction sheet (306). 'One system' was not 'wrong' but less functional in this context. The purpose with the free body diagram was to be an external representation of relevant forces in order to solve the questions on the instruction sheet. Olle's main argument was that the aim with the free body diagram in this context is to solve the physics problems. Thus, the free body diagram was not an objective in itself, but rather a tool to reach the objectives. 
301. 0 I would $[::()$.$] keep together=$ ((Olle points at the ox and box in his instruction sheet and gets Pia's and Rut's attention, see a))

302. R [mm]

303. $\mathrm{R} \mathrm{mm} \mathrm{(.)} \mathrm{so} \mathrm{it} \mathrm{is} \mathrm{one} \mathrm{system} \mathrm{so} \mathrm{it} \mathrm{is}$ the same ((Rut continues to draw only one box))

304.

305. $\mathrm{P}>$ or wha+ what did you say $<$ ? ((Pia points at Olle's sheet of instructions, see b))

306. 0 e:: well one should check (.) the forces in between too

((Olle points in his sheet of instructions again, but now specifically at the first question))

307. (0.6)

308. $\mathrm{P}>$ in between too so you should take them one at time $<$ then?

309. 0 yes

\section{P OK (0.6) well it says so here (.) in fact yes \\ ((Rut changes the force diagram into two systems again, see c))}

Figure 6. Excerpt 3

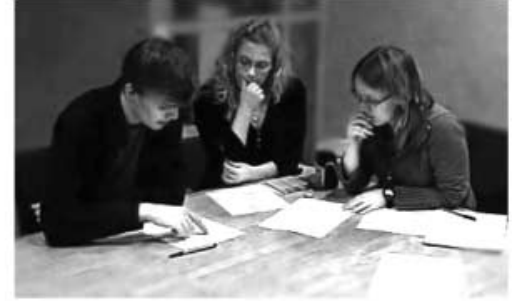

(a) Olle points at his instruction sheet

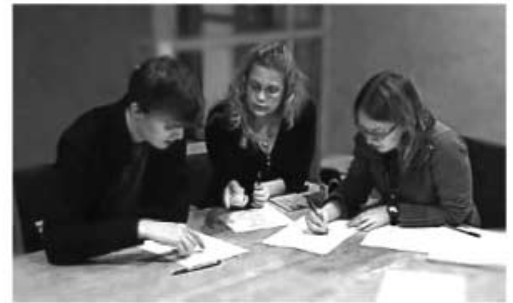

(b) Pia points at Olle's instruction sheet

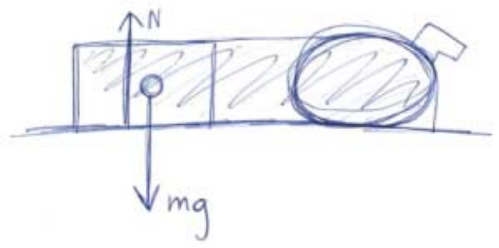

(c) The box and the ox, as 'two systems'

\subsection{Illustrating forces}

After the group decided to have two systems Rut continued to draw, with online commentaries, a normal force and a gravitational force on the ox. Following the tradition of scientific names (Lemke 1990), Rut gave the forces formal prefixes, $N_{1}$ and $N_{2}$ and $m_{1} g$ and $m_{2} g$, to separate them. Rut then started to draw a friction force:

In this excerpt Olle, Pia and Rut discussed which direction the friction force on the box should have. In the beginning of this excerpt, Rut communicated her view of the direction of the friction force on the box by drawing a force (Figure 7(a)) and called it a 'presumption' (403), she thereby used the free body diagram to illustrate an idea. Olle commented this by saying 'maybe' (405). Rut changed the arrow so it points backwards instead (Figure 7(b)) and at the same time Olle said that the friction force should probably be backwards (405). Rut did not acknowledge this, but looked down and continued drawing until Pia stated that she found that the direction of friction force can be tricky (407). This could be a topic initial elicitor (Button and Casey 1985), where, instead of discussing how to construct this particular free body diagram, Pia elicited a new possible topic by describing her experiences of constructing free body diagram. This discussion (401-409) was simultaneous with the production of the free body diagram, since Rut never lifted her pen from the paper, until this point. Then Rut looked up, smiled, rearranged her sleeves and said 'it doesn't 
401. $\mathrm{R}$ so it has (.) a friction force here $\uparrow$

402. (2.3)

403. $R$ can presume it is like ((see a))

404. (0.9)

405. 0 yes [maybe] (.)

((Rut rewrites the arrow, see b))

the fric[tion] force is probably

backwards (.) there

406. P [well I don't know which]

[di:]

407. P I never know which direction (.) it should be

408. (1.1)

409. 0 well it usually ah::

410. R it doesn't really matter (.) you get a negative force in that case ${ }^{\circ}$ huh ${ }^{\circ}$

((Rut looks and Olle and smiles and rearranges her sleeves, see c))

411. 0 yes exactly

412. R it works itself out the end (.) usually

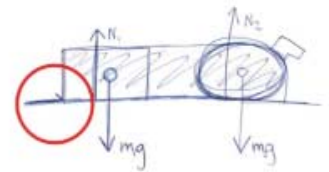

(a) Rut begins to make a friction force on the box

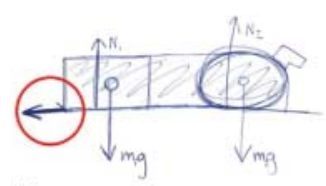

(b) Rut rewrites the friction force

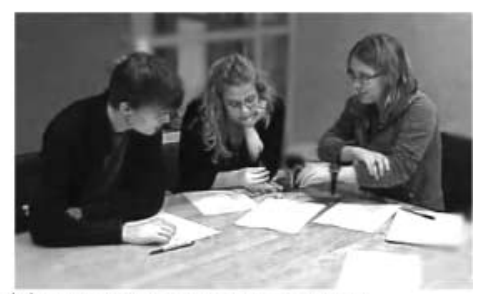

(C) Rut smiles and rearranges her sleeves

Figure 7. Excerpt 4.

really matter' (410). This statement together with Rut's rearranged embodied stance, (she did not write anymore but smiled and looked towards Olle), indicated that Rut wanted to introduce another new topic. Then she said that the free body diagram was still work in progress: 'it works itself out in the end' (412), and thereby separated the current form of the free body diagram from the end product.

\subsection{Explaining forces}

After Rut made the friction force backwards on the box, Pia returned to the topic of previous experience, and asked Olle and Rut how they were thinking when they decided that the direction of friction force on the box should be backwards. At this point, Rut stopped drawing and was looking up at Olle and Pia. Rut and Olle then elaborated orally on what they know from the picture on the sheet of instructions (if it is a totally friction free surface, and if it is it a rope between the ox and box). Olle also said that there should be a friction force on the ox forward, and pointed at the picture of the ox on his sheet of instructions, but this is not picked up by either Pia or Rut. Rut answered only ' $m m$ ' while she drew the friction force on the ox backwards (visible in and named $\mathrm{F}_{R 2}$ in Figure 8(b) and 8(c), and will be elaborated further on in next section). After this conversation, there was a shift in the interaction again and Pia asked about the first question on the instruction sheet:

In this excerpt, Pia again referred (501) to a part of a question from the instruction sheet by pointing at it (see Figure 8(a)). Again the topic changed to a focus on how the instructions are given. This is also shown by how Rut lifted her pen and turned herself towards Pia. When Rut answered Pia's question (505), Rut used the free body diagram and drew a force on the box at the same time. As a result, Rut added to the production of the free body diagram (see Figure 8(b)) 
501. P > but I mean< how are they related

((Pia points with her pen on her sheet of first question in the instruction sheet, Rut stops drawing, see a))

502. (1.2)

503. P eh sort of

504. (1.4)

505. R then there [is heh e::] (.) [then there is] ((Rut draws force on the box forward, see b))

506. P [I thought] should [they be the same] or?

507. $\mathrm{R}$ then there is

508. (0.6)

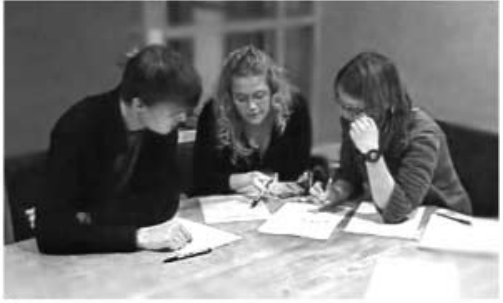

(a) Pia points on her sheet of instructions

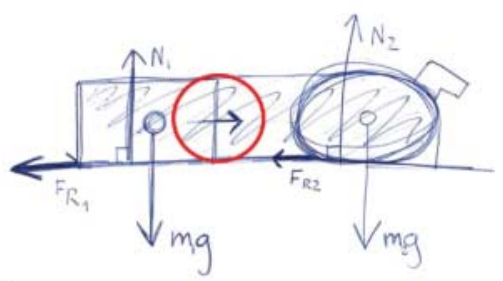

(b) Rut draws force on the box forward

509. R ${ }^{\circ}$ heh ${ }^{\circ}$

510. $\mathrm{R}$ if you draw a force diagram of the box then they would say there is a force there (.) and if you draw a force dia dia: (.) $\$$ gram\$ of the ox you would say there is a force $=$

511. $0 \mathrm{~mm}$

512. $\mathrm{R}=$ [backwards] there

((Rut draws the forces between the ox and the box while she is speaking, see c))

513. $\mathrm{P}[\mathrm{mm}]$

Figure 8. Excerpt 5.

at the same time as she answered Pia's question. Pia then asked 'should they be the same or' introducing sizes of forces to the discussion (506). Again Rut added to the production of the free body diagram (see Figure 8(c)) at the same time as she answered Pia's question (507, 510 and 512).

\subsection{Dealing with an error}

Before, Olle said that there should be a friction force forward while Rut drew the friction force $\mathrm{F}_{R 2}$ on the ox backwards, which can be seen in Figure 8(b) and 8(c). This has not been mentioned until half a minute later, when Olle points at the collective free body diagram:

Over again Olle argued that the friction force on the ox should be forward $(602,603)$, but this time his hand gesture was now directed towards a specific point in the free body diagram when he pointed at the collective response sheet (see Figure 9(a) and 9(b)), which he has not done before: together the pointing and talking established a larger contrast than talk alone (Goodwin 2000). This time Rut lifted up her pen and stopped drawing. Then she quickly drew over (very strongly this time) the arrow backwards on the ox, and drew a new arrow forward on the ox (see Figure 9(c)). Rut said (as in the third excerpt) that it would work itself out in the end, but this 
601. 0 So the friction force is going to be forward

((Olle points at the picture, Rut's hand is hesitating, see $a$ and $b$ ))

602. (2.3)

603. 0 for the ox should be able to (.) eh: well if eh the ox has [constant] (.) velocity then the $(0.6)$ friction force is forward

((Olle makes a circular gesture with his finger over the drawing))

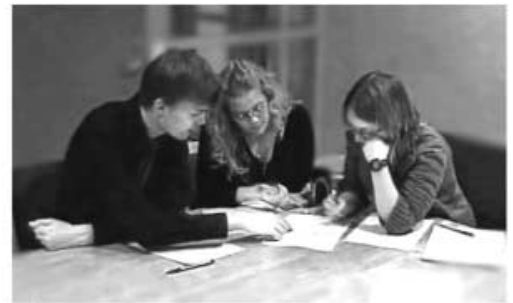

(a) Olle points at the force diagram

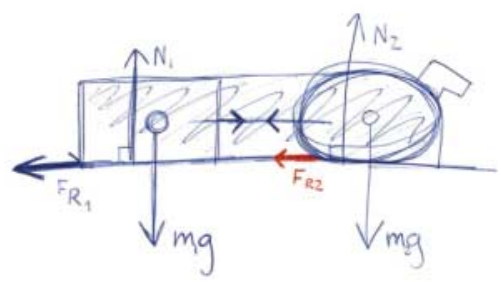

(b) The friction force $F_{R 2}$ is backwards

((Rut writes over the arrow $\mathrm{F}_{\mathrm{R} 2}$ backwards and makes a new arrow $\mathrm{F}_{\mathrm{R} 2}$ forward, see c))

605. $\mathrm{R}>$ As I said (.) had I done the calculations it would just have come out negative [(.) and then] we would have had to change it < ((Rut giggles and adjusts the picture))

606. 0

[yes exactly]

$607.0^{\circ}$ yes $^{\circ}$

608. (0.6)

609. $\mathrm{P}{ }^{\circ}>0$ my dear $<$ think that you can $={ }^{\circ}$

$610.0=$ it was not wrong rather it was $\downarrow$

611. (3.0)

Figure 9. Excerpt 6.

time her fast talking and her giggles indicated that this error is slightly more severe this time. Pia's answer 'o my dear, think that you can' (609) verified that the wrong direction a friction force in the free body diagram was different this time compared to the previous time. Likewise Olle's statement that 'it was not wrong rather it was' (610) and the relatively long silence (611) afterwards confirmed this analysis.

\section{Discussion}

As mentioned before, the six excerpts presented here represented the whole data set, (the major part of it at least), in the sense that students did not talk off topic and the students also cooperated well. However, in the presented results the details in the students' conversation revealed that the students during this small sequence also did misunderstand each other (303) and did not always listen to each other's arguments, (see Section 3.5). In other words, although the results illustrate an 'ideal learning situation' where engineering students produce a (correct) free body diagram 
together, these excerpts do also demonstrate how the problem-solving processes do not happen from $A$ to $B$ : the processes of learning are naturally complex. The analytical framework of CA revealed different features of these processes of solving physics problems together, several of them related to the free body diagram.

The free body diagram had several functions in the students' problem-solving process. First of all, the free body diagram had to be functional in terms of answering the questions on the instruction sheet (Section 3.3), which is in line with how free body diagrams usually are described (Kleppner and Kolenkow 1973). In this study, the free body diagram was part of a correct answer and the end product of the students' conversation, and thereby the embarrassment of getting it wrong, illustrated in Section 3.6. Secondly, the free body diagram was also used to illustrate suggestions in the problem-solving process (Section 3.4), and it was also helpful when explaining (or teaching) conceptual issues, such as Newton's third law (Section 3.5). Moreover, the results illustrate that the students communicate many things through the response sheet, and only through the response sheet. The student Rut in our study exemplified this when she communicated many conceptual issues through drawing the free body diagram. For example, Rut simplified the ox and box (compared to the picture in the sheet of instruction), and named the normal force and the gravitational force on the box in the free body diagram to ' $\mathrm{N}$ ' and ' $\mathrm{mg}$ ', respectively, without any further comments. Much physics was communicated only through the free body diagram in our sequence, which is in line with earlier research of engineering discourse. Engineering students tend to let data speak for itself and that efficiency serves as guiding ideology (Kittleson and Southerland 2004). To only analyse what the students say and omitting what the students $d o$, like in earlier studies (Ingerman, Berge, and Booth 2009) would therefore not give us the full picture of group work as a practice.

Surprisingly little research has taken the role of tools and material into account, despite engineering education being 'probably one of the most material-saturated disciplines' (Johri and Olds 2011, 161). In line with this argument we would like to add that it is also necessary to investigate what types of learning opportunities and roles that go along with implementing students to collaboratively work with tools, such as simulation programs, in engineering education.

Changing focus to Olle's and Pia's roles in this study, these two students communicated mainly through oral speech and through pointing at the sheet of instruction and the not yet finished free body diagram: the sheet of instruction and the not yet finished free body diagram became mutual resources for the group. However, Olle's and Pia's pointing rather reinforced their arguments to changes of the free body diagram than contributed to actual production of it. Plainly, the students in the presented results did not communicate on the same terms. The student who produced the free body diagram expressed 'more physics' than the students that were sitting next to her, watching. This has relevance for other collaborative work such as working with simulations, modelling or lab work. If students work together as a pair or more it is relevant to question if the students have the same learning possibilities, i.e. the same possibilities to communicate and to produce data, since the students have a tendency to let data speak for itself. Here it is necessary to also point out that although Olle and Pia do not produce the free body diagram on the same terms as Rut, they both played significant roles in the collective learning process. The most striking example might be that Olle contributed to the problem-solving process with (correct) suggestions (lines 301, 306, 405 and 603). Pia on the other hand pointed out a misunderstanding $(305,308)$, but even more importantly, she drew attention to critical aspects of the task $(407,506)$.

In summary, the use of CA has been both worthwhile and beneficial, because CA highlights what the students do and make the students' learning processes more transparent. In this study all three students contributed to well-functioning group dynamics, both as speakers and as active listeners, the group continued to solve the other (more difficult) physics questions and tasks. This is line with the well-known fact that if the group dynamics is good students can solve more difficult problems than the strongest student in the group (Heller and Hollabaugh 1992a). 


\section{Implications}

Based on our detailed examinations of group work dynamics, we can provide a few implications for educational practice in this context:

- The importance of giving clear instructions. This is important for many reasons, but here we have showed how the way that the task is constructed does not only affect the quality and efficiency of the following conversation but also changes the conditions for communication within the group.

- There are consequences and constraints of having a collective response sheet. A collective response forces the students to collaborate and coordinate their understandings, since they are presumed to agree on the same answers. In addition, when not having the possibility to write and draw the students without a pen are forced to communicate by talking to a higher extent, which is one of the arguments for advocating group work as a teaching form in the first place: the possibility to practice talking science (Lemke 1990). However, a collective response sheet infers that the students do not communicate on the same terms.

- The benefits of circulating roles in group work. Due to fear of imbalanced power relations when students learn physics together, teachers and tutors have in earlier research been recommended the strategy of giving students specific roles which circulate, such as 'the executive manager', 'the sceptic' and 'the secretary', (Benckert and Pettersson 2008; Heller and Hollabaugh 1992b). Our research supports that strategy. Partly because the group of students in our study successfully used a similar structure, and partly because roles which circulate would make the students communicate on the same terms.

- The free body diagram has an embedded history. Much of the students' communication becomes visible on the response sheet only, and this characteristic is an important part of the group work. In addition, the embedded history of the free body diagram also gives a visiting tutor important possibilities to follow up and articulate earlier misunderstandings.

\section{Acknowledgements}

The authors are grateful to the participating students who shared their time and learning experience and to the teachers, with whom we collaborated. We thank Professor Shirley Simon for the support and encouragement, valuable feedback on earlier version of the article and for useful comments on the final version.

\section{References}

Airey, J. 2009. Science, Language, and Literacy: Case Studies of Learning in Swedish University Physics. Uppsala: Acta Universitatis Upsaliensis.

Benckert, S., and Pettersson, S. 2008. "Learning Physics in Small-Group Discussions - Three Examples.” Eurasia Journal of Mathematics, Science \& Technology Education 4 (2): 121-134.

Berge, M. 2011. Group Work and Physics: Characteristics, Learning Possibilities and Patterns of Interaction. Göteborg: Chalmers University of Technology.

Berge, M., and Danielsson, A. 2013. "Characterising Learning Interactions: A Study of University Students Solving Physics Problems in Groups.” Research in Science Education 43 (3): 1177-1196. doi:10.1007/s11165-012-9307-0.

Berge, M., A. T. Danielsson, and Å. Ingerman. 2012. "Different Stories of Group Work: Exploring Problem Solving in Engineering Education." NorDiNa 8 (1): 3-16.

Button, G., and N. Casey. 1985. "Topic Nomination and Topic Pursuit.” Human Studies 8 (1): 3-55.

Case, J. M., and G. Light. 2011. "Emerging Methodologies in Engineering Education Research.” Journal of Engineering Education 100 (1): 186-210.

De Graaff, E., and A. Kolmos. 2003. "Characteristics of Problem-Based Learning." International Journal of Engineering Education 19 (5): 657-662.

Flores, S., S. E. Kanim, and C. H. Kautz. 2004. "Student Use of Vectors in Introductory Mechanics.” American Journal of Physics 72 (4): 460-468. doi:10.1119/1.1648686.

Goodwin, C. 2000. "Action and Embodiment within Situated Human Interaction.” Journal of Pragmatics 32 (10): 1489-1522. 
Goodwin, C. 2007. "Participation, Stance and Affect in the Organization of Activities." Discourse Society 18 (1): 53-73.

Greiffenhagen, C. 2008. "Video Analysis of Mathematical Practice? Different Attempts to 'Open Up' Mathematics for Sociological Investigation." Qualitative Sozialforschung/Forum: Qualitative Social Research 9(3, Art. 32 - September 2008). http://nbn-resolving.de/urn:nbn:de:0114-fqs0803323.

Have, P. T. 2007. Doing Conversation Analysis. 2nd ed. London: Sage.

Heller, P., and M. Hollabaugh. 1992a. "Teaching Problem Solving Through Cooperative Grouping. Part 1: Group Versus Individual Problem Solving." American Journal of Physics 60 (7): 627-636.

Heller, P., and M. Hollabaugh. 1992b. "Teaching Problem Solving through Cooperative Grouping. Part 2: Designing Problems and Structuring Groups.” American Journal of Physics 60 (7): 637-644. doi:10.1119/1.17118.

Heritage, J., and T. Stivers. 1999. "Online Commentary in Acute Medical Visits: A Method of Shaping Patient Expectations." Social Science \& Medicine 49 (11): 1501-1517.

Hestenes, D., G. Wells, and G. Swackhamer. 1992. "Force Concept Inventory.” The Physics Teacher 30 (March): 141-153.

Hindmarsh, J., and C. Heath. 2007. "Video-Based Studies of Work Practice." Sociology Compass 1 (1): $156-173$. doi:10.1111/j.1751-9020.2007.00012.x

Hubber, P., R. Tytler, and F. Haslam. 2010. "Teaching and Learning about Force with a Representational Focus: Pedagogy and Teacher Change." Research in Science Education 40 (1): 5-28. doi:10.1007/s11165-009-9154-9.

Ingerman, ̊̊., M. Berge, and S. Booth. 2009. "Physics Group Work in a Phenomenographic Perspective-Learning Dynamics as the Experience of Variation and Relevance." European Journal of Engineering Education 34 (4): 349-358.

Johri, A., and B. M. Olds. 2011. "Situated Engineering Learning: Bridging Engineering Education Research and the Learning Sciences.” Journal of Engineering Education 100 (1): 151-185.

Kittleson, J. M., and S. A. Southerland. 2004. "The Role of Discourse in Group Knowledge Construction: A Case Study of Engineering Students.” Journal Of Research In Science Teaching 41 (3): 267-293. doi:10.1002/Tea.20003.

Kleppner, D., and R. J. Kolenkow. 1973. An Introduction to Mechanics. New York: McGraw-Hill.

Kolmos, A., N. Mejlgaard, S. Haase, and J. E. Holgaard. 2013. "Motivational Factors, Gender and Engineering Education." European Journal of Engineering Education 38 (3): 340-358. doi:10.1080/03043797.2013.794198.

Koschmann, T., and A. Zemel. 2009. "Optical Pulsars and Black Arrows: Discoveries as Occasioned Productions." Journal of the Learning Sciences 18 (2): 200-246.

Lemke, J. L. 1990. Talking Science: Language, Learning, and Values. Norwood, NJ: Ablex.

Lindwall, O., and G. Lymer. 2008. "The Dark Matter of Lab Work: Illuminating the Negotiation of Disciplined Perception in Mechanics." Journal of the Learning Sciences 17 (2): 180-224.

Macho-Stadler, E., and M. Jesús Elejalde-García. 2013. "Case Study of a Problem-Based Learning Course of Physics in a Telecommunications Engineering Degree." European Journal of Engineering Education 38 (4): $408-416$. doi:10.1080/03043797.2013.780012.

Mondada, L. 2007. "Multimodal Resources for Turn-Taking: Pointing and the Emergence of Possible Next Speakers." Discourse Studies 9 (2): 194-225. doi:10.1177/1461445607075346.

Oliveira, P. C., and C. G. Oliveira. 2013. "Using Conceptual Questions to Promote Motivation and Learning in Physics Lectures." European Journal of Engineering Education 38 (4): 417-424. doi:10.1080/03043797.2013. 780013.

Prince, M. 2004. "Does Active Learning Work? A Review of the Research.” Journal of Engineering Education 93 (3): 223-231.

Redish, E. F. 2003. Teaching Physics: With the Physics Suite. Hoboken, NJ: John Wiley \& Sons.

Sahin, M. 2010. "The Impact of Problem-Based Learning on Engineering Students' Beliefs about Physics and Conceptual Understanding of Energy and Momentum." European Journal of Engineering Education 35 (5): 519-537. doi:10.1080/03043797.2010.487149.

Schegloff, E. A. 1992. "Repair after Next Turn - the Last Structurally Provided Defense of Intersubjectivity in Conversation.” American Journal of Sociology 97 (5): 1295-1345.

Scherr, R. E., and D. Hammer. 2009. "Student Behavior and Epistemological Framing: Examples from Collaborative Active-Learning Activities in Physics." Cognition and Instruction 27 (2): 147-174.

Waller, E., and M. H. Kaye. 2012. “Teaching Problem-Solving Skills to Nuclear Engineering Students.” European Journal of Engineering Education 37 (4): 331-342. doi:10.1080/03043797.2012.691871.

\section{About the authors}

Maria Berge holds a PhD in Engineering Education Research and an MS degree in Physics Engineering from Chalmers University of Technology. She works currently as a Post-doctoral Fellow at the Department of Science and Mathematics Education at Umeå University, Sweden.

Alexandra Weilenmann holds a PhD in informatics and is Associate Professor in applied information technology. She is employed at the Department of Applied Information Technology at the University of Gothenburg/Chalmers, Sweden. 
